\title{
Towards a more thoughtful use of mould prediction models - A critical view on experimental mould growth research
}

\author{
EVy VeREeCKen ${ }^{1, *}$ KRISTOF VANOIRBEeK $^{2}$ and Staf Roels ${ }^{3}$
}

${ }^{1}$ KU Leuven, Building Physics Section, Kasteelpark Arenberg 40 - box 2447, B-3001 Leuven, Belgium

Evy.Vereecken@bwk.kuleuven.be

${ }^{2}$ KU Leuven, Centre for Food and Microbial Technology, Kasteelpark Arenberg 23 box 2457, B-3001 Leuven, Belgium

Kristof.Vanoirbeek@biw.kuleuven.be

${ }^{3}$ KU Leuven, Building Physics Section, Kasteelpark Arenberg 40 - box 2447, B-3001 Leuven, Belgium

Staf.Roels@bwk.kuleuven.be

\footnotetext{
*Author to whom correspondence should be addressed

Evy Vereecken, KU Leuven, Building Physics Section, Kasteelpark Arenberg 40, B-3001 Leuven, Belgium, tel.: +32 16321098, Fax: +32 16321980, email: Evy.Vereecken@bwk.kuleuven.be
} 


\section{Abstract}

To assess the mould risk on materials, different mould prediction models are available. Each of these models struggles, however, with shortcomings, which might result in widely varying conclusions. A view on the challenges might come in use when developing novel or upgraded models in view of a more reliable risk assessment. Additionally, this knowledge will stimulate a more thoughtful use of the current models.

This paper shows a preliminary evaluation of some mould prediction models, and this based on experimental literature data on wood. Although experiments are the input for the model development, discrepancies are observed. Therefore, the difficulties and challenges in experimental mould research are discussed.

\section{Key words:}

Mould risk, mould prediction models, mould growth, mould index, laboratory experiments, Aspergillus restrictus

\section{Introduction}

Mould growth on building materials can have a large impact on the degradation of materials (Koestler et al., 2003; Viitanen et al., 2010; Sterflinger, 2010; a.o.). As it acts as a precursor of wood decay, a serious consideration of the risk on mould growth is furthermore of importance when dealing with wooden structures. 
Additionally, mould growth can negatively influence the occupant's well-being (Platt et al., 1989; Lacey, 1994; Baughman and Arens, 1996, Piecková and Jesenská, 1999; Burr et al., 2007; a.o). Hence, mould growth in buildings should be avoided as also denoted by the World Health Organization (WHO, 2009). In order to predict the mould risk on building surfaces, currently, in addition to the temperature ratio (Hens, 1991) - a ratio that can be calculated in the design stage to achieve building nodes subjected to a limited mould risk - also other, more advanced mould prediction models are available. For instance, the VTT model (Hukka and Viitanen, 1999), Sedlbauer's isopleths (Sedlbauer, 2001; Krus and Sedlbauer, 2002), Sedlbauer's biohygrothermal model (Sedlbauer, 2001; Sedlbauer and Martin, 2003), etc. are frequently used in mould risk assessments performed in the building physics area (Karagiozis and Salonvaara, 2001; Krus et al., 2007; Abuku et al., 2009; Langmans and Roels, 2014; a.o.). These models include the main influencing factors for mould growth: the surface temperature and the relative humidity. Additionally, in some of them other factors such as, for instance, the substrate and mould species are included as well. It is, however, important to note that, apart from the considered influencing factors, all of the current mould prediction models are based on either simplifications or assumptions. For example, the isopleth systems are developed based on steady-state experiments, the VTT model is developed starting from mould growth on wood, etc. Furthermore, the criterion that indicates the mould risk can differ for the diverse models. Due to all those shortcomings and discrepancies, widely varying results and conclusions can be obtained, as shown in (Vereecken and Roels, 2012). 

research. Journal of Building Physics 39(2): 102-123.

To get a better view on the validity of the current mould prediction models, a comparison between numerical and experimental results is needed. Additionally, a critical analysis of the experimental approach applied to develop mould prediction models is desirable. So far, mould growth research and the development of mould prediction models is mainly performed based on experimental studies in the laboratory (Hukka and Viitanen, 1999; Sedlbauer, 2001; Ojanen et al., 2010; a.o.). Mould growth development is, however, a highly complex microbiological process. Hence, achieving an acceptable agreement between the experimental simulated mould growth process in test conditions and the mould growth development in the actual built environment is challenging. Knowledge on the challenges to deal with in experimental mould growth research will stimulate a more thoughtful use of the mould prediction models. This awareness is, furthermore, of main importance when developing novel models or when upgrading the current models and, hence, comes in handy on the road towards a more reliable mould risk assessment.

To provide a view on the validity of the main mould prediction models currently applied in the building physics field, in section 2 a comparison between experimental laboratory results found in the literature and numerical predictions is made. Since such experimental studies serve as the input for the development of mould prediction models, an acceptable agreement between numerical and experimental findings would be expected. Yet, the rather poor agreement obtained in this comparison, necessitates further research to explain potential differences. Thereto, in section 3 , a number of difficulties and challenges in experimental mould growth research are tackled. To end, the main findings are discussed. 
Note that the authors already published a critical review paper on mould prediction models (Vereecken and Roels, 2012) in which the main mould prediction models used in the building physics field were compared based on numerical simulations. In the current paper, such numerical mould predictions will be compared to real experimental results. Additionally, a number of uncertainties in experimental mould growth research will be raised.

\section{Evaluation of mould prediction models based on literature data}

As a preliminary study on the validity of the mould prediction models currently available, experimental literature data of mould growth on wood are compared with the numerical results obtained based on the current mould prediction models. Wood was chosen because it facilitates an evaluation of the VTT model, which is originally developed for wood. After all, the coefficients to study other materials are currently developed for a small set of materials and could hence include inaccuracies which may contribute to the deviations between numerical predictions and experimental work. It is important to note that based on the comparison carried out in this paper no general conclusions on the mould prediction models are intended. For this, a more extensive study - including more data, and this for different building materials, as well as a fully consideration of the applied experimental methodology - is needed. The current evaluation, however, aims a first indication of the reliability of the analysed models. 


\section{Experimental mould growth studies on wood}

The mould growth development predicted by the different models will be compared to the measurements performed by Nielsen et al. (2004) and by Johansson et al. (2013a). The former research focused on different steady-state conditions (see upper part of Table 1), while the second studied the influence of transient conditions (see lower part of Table 1). For a description of the inoculation, incubation, etc., applied in both studies, the reader is referred to Nielsen et al. (2004) and Johansson et al. (2013a).

Based on the two considered studies, the difference in mould growth indication applied in different mould growth studies can already be raised as a first issue in the present mould research. Indeed, whereas Nielsen et al. (2004) describes the mould growth development based on the surface percentage covered by mould, Johansson et al. (2013a) defines a rating scale that indicates the extent of growth by a $40 x$ magnification. Such a difference in mould growth indication complicates a comparison, and consequently an evaluation, of the different studies. To enable a comparison, in the current study, the mould indications applied in the considered studies have been linked to the VTT mould index (Viitanen and Ojanen, 2007; Ojanen et al., 2010), as shown in

Table 2. 
Table 1. Test conditions (incubation temperature and relative humidity) applied by Nielsen et al. (2004) and Johansson et al. (2013a).

\begin{tabular}{|c|c|c|c|c|c|c|}
\hline & Time $_{1}$ & $\mathrm{RH}_{1}(\%)$ & $\mathrm{T}_{1}\left({ }^{\circ} \mathrm{C}\right)$ & Time $_{2}$ & $\mathrm{RH}_{2}(\%)$ & $\mathrm{T}_{2}\left({ }^{\circ} \mathrm{C}\right)$ \\
\hline \multicolumn{7}{|c|}{ Nielsen et al. (2004) } \\
\hline $\bar{A}$ & Constant & 78 & 25 & & & \\
\hline B & Constant & 86 & 25 & & & \\
\hline C & Constant & 86 & 20 & & & \\
\hline $\mathrm{D}$ & Constant & 90 & 20 & & & \\
\hline$E$ & Constant & 95 & 10 & & & \\
\hline $\mathrm{F}$ & Constant & 90 & 10 & & & \\
\hline \multicolumn{7}{|c|}{ Johansson et al. (2013a) } \\
\hline $\mathrm{G}$ & Constant & 90 & 22 & & & \\
\hline $\mathrm{H}$ & 7 days & 90 & 22 & 7 days & 60 & 22 \\
\hline 1 & 12 hours & 90 & 22 & 12 hours & 60 & 22 \\
\hline J & Constant & 90 & 10 & & & \\
\hline K & 7 days & 90 & 22 & 7 days & 90 & 5 \\
\hline
\end{tabular}

Table 2. Microscopic coverage (Nielsen et al., 2004) and rating scale in function of the extent of growth by a 40x magnification (Johansson et al., 2013a) together with the adopted corresponding VTT mould index (Viitanen and Ojanen, 2007; Ojanen et al., 2010). 


\begin{tabular}{|c|c|c|c|}
\hline $\begin{array}{l}\text { VTT } \\
\text { mould } \\
\text { index }\end{array}$ & $\begin{array}{l}\text { Nielsen's } \\
\text { microscopic } \\
\text { coverage }\end{array}$ & $\begin{array}{l}\text { Johansson's } \\
\text { rating scale }\end{array}$ & $\begin{array}{l}\text { Extent of } \\
\text { mould growth }\end{array}$ \\
\hline 0 & $0 \%$ & 0 & No mould growth \\
\hline 1 & $\sim 5 \%$ & 1 & $\begin{array}{l}\text { Initial growth, one or a few hyphae } \\
\text { and no conidiophores (branched } \\
\text { fungal hypha that produces conidia } \\
\text { (spores)) }\end{array}$ \\
\hline 2 & $<10 \%$ & 2 & $\begin{array}{l}\text { Sparse but clearly established } \\
\text { growth; often conidiophores } \\
\text { are beginning to develop }\end{array}$ \\
\hline 3 & $<50 \%$ & & \\
\hline 4 & $>50 \%$ & & \\
\hline 5 & $>70 \%$ & 3 & $\begin{array}{l}\text { Patchy, heavy growth with many } \\
\text { well-developed conidiophores }\end{array}$ \\
\hline 6 & $\begin{array}{l}\text { Around } \\
100 \%\end{array}$ & 4 & $\begin{array}{c}\text { Heavy growth over more or less the } \\
\text { entire surface }\end{array}$ \\
\hline
\end{tabular}

The measurements performed by Nielsen et al. (2004) and Johansson et al. (2013a) are, together with the corresponding mould index (see

Table 2), shown in Figure 1. It should be noted that the results given by Johansson et al. (2013a) are presenting a median rating of 6 specimens in each test scheme. The results given by Nielsen et al. (2004) are the average growth determined on four samples. For those samples, a standard deviation ranging from 10 till $30 \%$ was 
found. The potential uncertainty in mould growth measurements and hence the need to go to stochastic models can also be observed by comparing the experimental results after 30 weeks for test scheme $C$ and $D$ (Figure 1a). For an identical temperature, a relative humidity equal to $86 \%$ (test scheme $\mathrm{C}$ ) was found to result in a larger growth rate than found for a relative humidity of $90 \%$ (test scheme D). Caution is thus required when interpreting the results.

As regards the transient conditions, Johansson et al. (2013a) showed a delay caused by the fluctuations between favourable and unfavourable relative humidity levels (Test $\mathrm{H}$, I in Table 1 and in Figure 1b). The influence of the period exposed to the low relative humidity was also clearly visible. A longer period exposed to an unfavourable relative humidity level $($ Test $\mathrm{H})$ resulted in a larger delay of the mould growth process than found for shorter unfavourable periods (Test I). 

use of mould prediction models - A critical view on experimental mould growth research. Journal of Building Physics 39(2): 102-123.

(a)

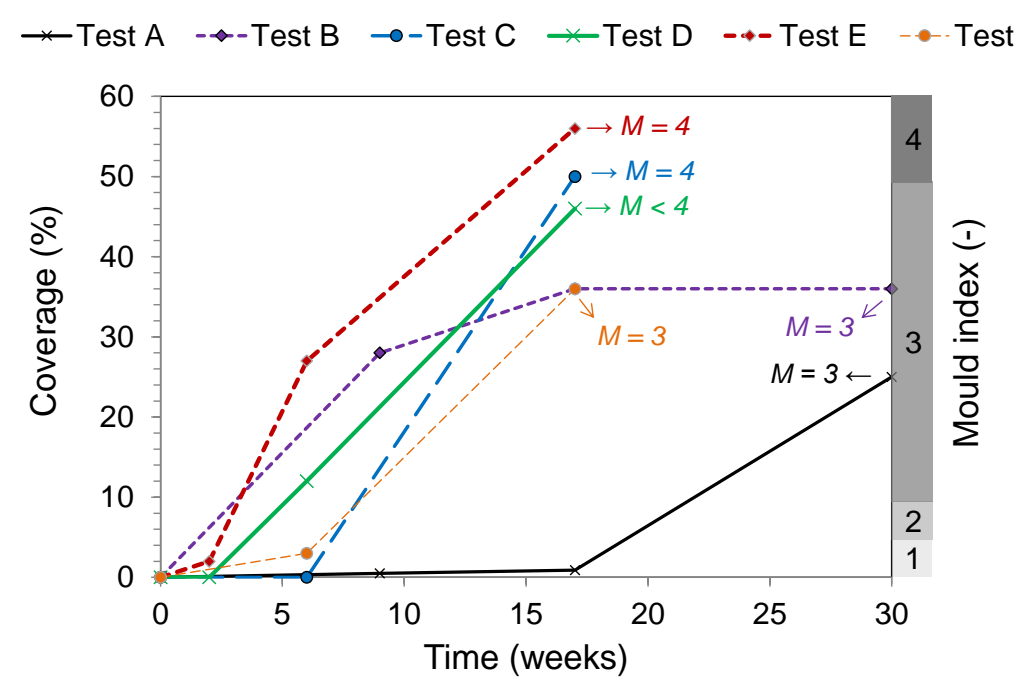

(b)

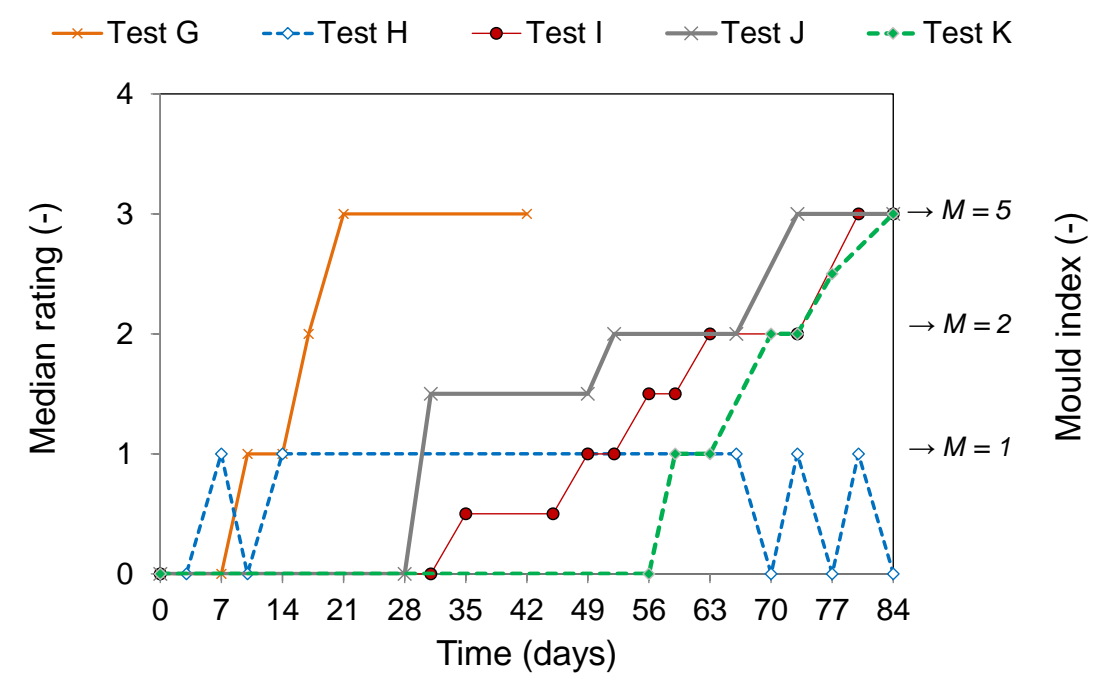

Figure 1. (a) Mould coverage on pine sapwood measured by Nielsen et al. (2004), (b) mould growth rating on a newly planed pine sapwood surface measured by Johansson et al. (2013a). For both studies, the corresponding mould index is indicated as well. The test conditions can be found in Table 1. 


\section{Numerical comparison}

The comparison made in the current paper focusses on measurements performed on pine sapwood. In this way, the reliability of the original VTT model $(\mathrm{W}=0$ for pine sapwood) can be studied. A study of the reliability of the original VTT model is expected to be of primary importance before evaluating the updated VTT model for other materials. In addition to the VTT model, a comparison with Sedlbauer's isopleth system, the biohygrothermal model and the mould index determined with WUFI-Bio (WUFI-Bio, 2011) will be made. For the latter three models, substrate category I (Sedlbauer, 2001) is assumed, which includes biologically recyclable and biologically degradable raw building materials. For transient conditions, Sedlbauer's isopleth system is applied as suggested in Moon's germination graph method (Moon, 2005). In this method, each curve in the isopleth system is indicated by a certain required exposure time for initiation of mould germination. For each curve, the associated accumulated exposure time can be recorded. When the accumulated exposure time for a group is equal or larger than its required exposure time, mould growth can start. For a full description of the different mould prediction models, the reader is referred to (Vereecken and Roels, 2012).

Because of the difficulty of comparing the mould growth in millimeters to the mould index, the comparison between the experimental findings and the mould growth prediction in millimeters is made by evaluating the mould risk based on the 'signal light'-rule (WUFI-Bio, 2011). This rule defines the mould risk based on the mould growth per year: 
- Mould growth > 200 mm/year: 'red light', not acceptable;

- $50 \mathrm{~mm} /$ year < mould growth < 200 mm/year: 'yellow light', additional evaluation is necessary;

- Mould growth < 50 mm/year: 'green light', usually acceptable.

A rough comparison between the experimental findings and the results obtained based on the mould prediction models is made in Table 3. For some of the test conditions the mould growth is over- or underestimated by the models. Some of these differences between the experimental and the numerical predicted mould growth are discussed by comparing Figure 1 with Figure 2, which shows the mould growth as a function of time. A more extended discussion can be found in (Vereecken, 2013).

For test scheme A, Nielsen et al. (2004) found after 30 weeks an average mould coverage of approximately $25 \%$ (Figure 1a), which can be characterised by a mould index equal to 3 . In contrast, the simulated mould indices remain (almost) zero (Figure 2a). Thus, although mould growth is observed in the experimental study, no mould risk is predicted based on the VTT model or the WUFI-Bio mould index. This underestimation of the predicted mould index is even more pronounced for test scheme I (Figure 1b versus Figure 2c). Moon's germination graph method (based on Sedlbauer's isopleth system) and the biohygrothermal model results for test scheme A after 30 weeks in $82 \mathrm{~mm}$ and $56 \mathrm{~mm}$ mould growth, respectively (Figure 2b). On a yearly basis this gives a mould growth larger than $50 \mathrm{~mm}$ but lower than $200 \mathrm{~mm}$, 
which agrees with the yellow light in the 'signal light'-rule. Hence, based on these models an additional mould risk evaluation is recommended. This is already in closer agreement with the experimental results (test scheme $A$ in Figure 1a) than found based on the mould index.

Table 3. Overview of the over- and underestimations obtained based on the mould prediction models for wood exposed to the different test schemes (see Table 1). Note that only the clearly pronounced differences are indicated. A negative/positive sign indicates an underestimation/overestimation based on the prediction model. More than one sign indicates a large difference.

\begin{tabular}{|c|c|c|c|c|c|c|c|c|c|c|c|}
\hline $\begin{array}{r}\text { Test } \\
\text { scheme }\end{array}$ & \multicolumn{6}{|c|}{ Nielsen et al. (2004) } & \multicolumn{5}{|c|}{$\begin{array}{l}\text { Johansson et al. } \\
\qquad(2013 a)\end{array}$} \\
\hline Model & A & B & C & D & $\mathbf{E}$ & $\mathbf{F}$ & $\mathbf{G}$ & $\mathbf{H}$ & I & J & K \\
\hline VTT original & - & $\approx$ & - & $\approx$ & + & $\approx$ & - & $\approx$ & - & - & - \\
\hline $\begin{array}{l}\text { Moon's } \\
\text { germination } \\
\text { graph method } \\
\text { with linear } \\
\text { interpolation } \\
\text { (Sedlbauer I) }\end{array}$ & $\approx$ & $\approx$ & $\approx$ & $\approx$ & $\approx$ & $\approx$ & $\approx$ & $\begin{array}{l}+ \\
+ \\
+\end{array}$ & $\approx$ & $\approx$ & $\approx$ \\
\hline $\begin{array}{l}\text { Biohygrothermal } \\
\text { model }\end{array}$ & $\approx$ & $\approx$ & $\approx$ & $\approx$ & $\approx$ & $\approx$ & $\approx$ & $\begin{array}{l}+ \\
+ \\
+\end{array}$ & $\approx$ & $\approx$ & $\approx$ \\
\hline $\begin{array}{l}\text { Mould index } \\
\text { based on results } \\
\text { biohyrothermal } \\
\text { model } \\
\text { (WUFI-Bio M) }\end{array}$ & - & $\begin{array}{c}+ \\
\text { (after } \\
30 \\
\text { weeks) }\end{array}$ & - & $\approx$ & $\approx$ & - & - & $\approx$ & - & - & - \\
\hline
\end{tabular}


When comparing the mould growth rate at the beginning, mainly for test scheme B a large difference between the experimental results and the numerically determined VTT mould index is found (Figure 1a versus Figure 2a). Whereas the experiment shows an immediate start of the mould growth (Figure 1a), the calculated mould index increases gradually (Figure 2a). Note however that - as mentioned earlier Nielsen et al. (2004) showed the mean values for the mould coverage found on four samples. A standard deviation ranging from 10 till $30 \%$ was found. This indicates the large potential spread in mould growth results.

Ultimately, it should be noted that the predicted mould indices and the mould growth for test scheme I (short unfavourable periods) is slightly lower than found for test scheme $\mathrm{H}$ (long unfavourable periods), as shown in Figure 2. This is in contrast with the experimental findings by Johansson et al. (2013a). 

use of mould prediction models - A critical view on experimental mould growth research. Journal of Building Physics 39(2): 102-123.

(a)

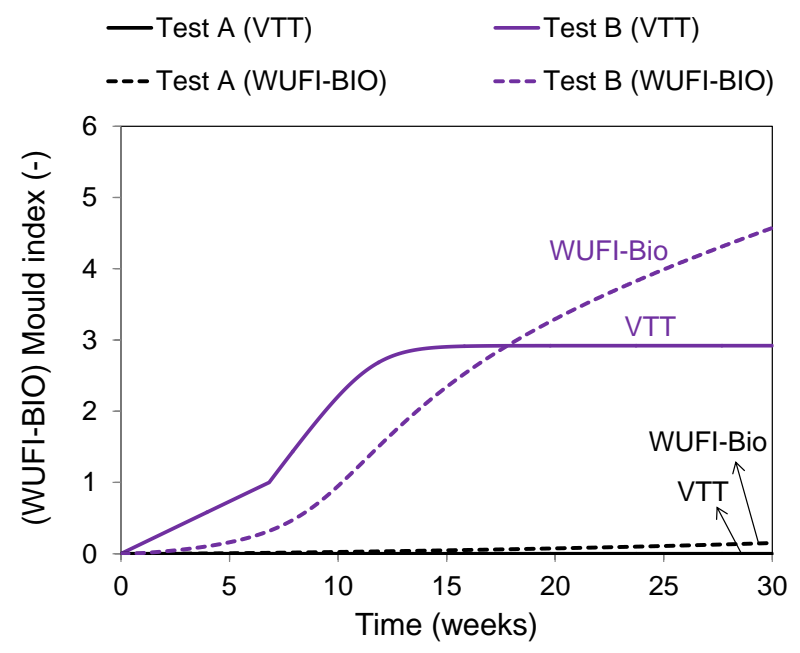

(c)

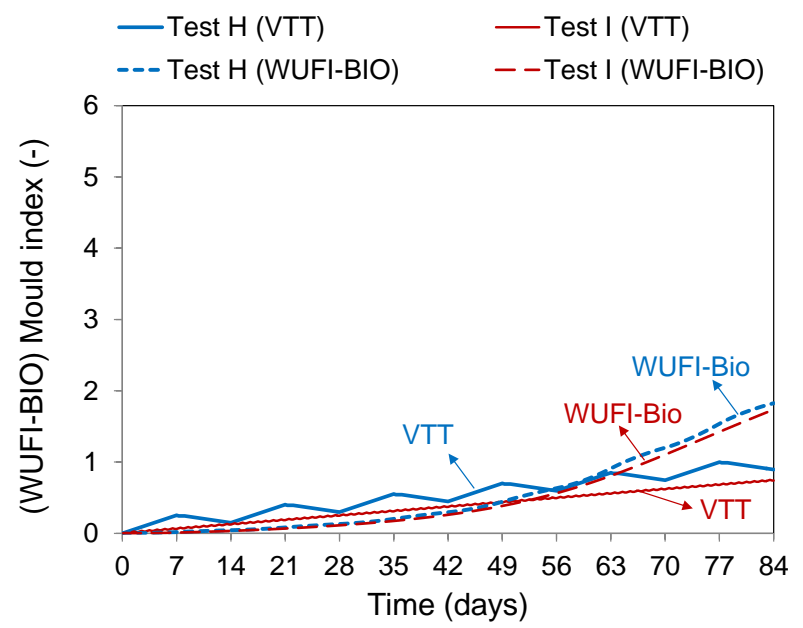

(b)

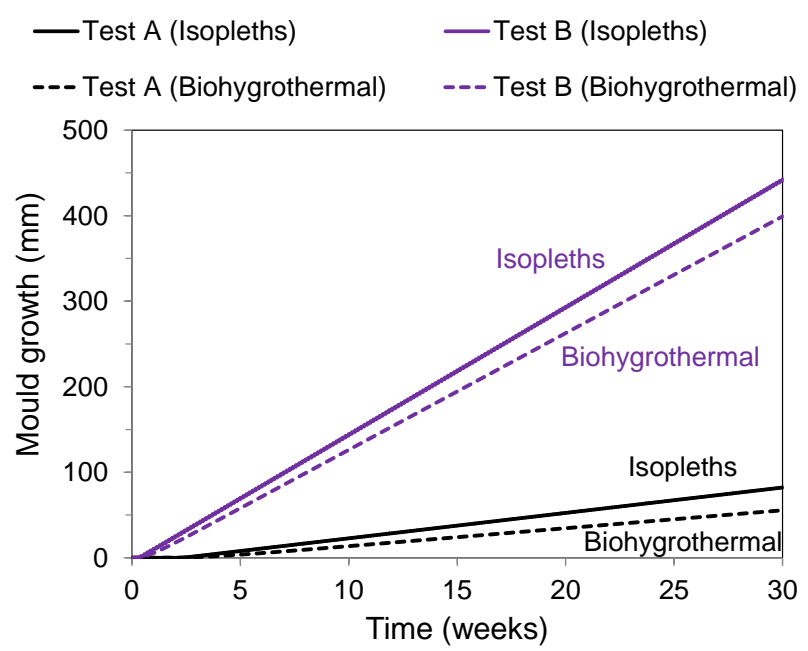

(d)

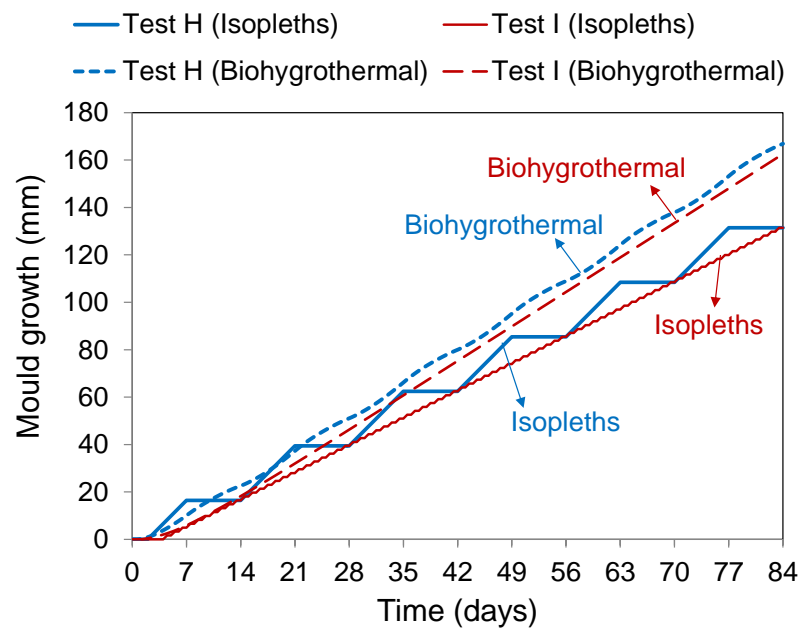

Figure 2. Mould growth development for the test schemes A, B, H and I (see Table 1): (a,c) (WUFI-BIO) mould index, $(\mathbf{b}, \mathbf{d})$ mould growth in millimeters. 


\section{Preliminary discussion}

Despite the large potential spread or uncertainty on the experimental results, a comparison between the experimental results and the predicted mould indices and mould growth in millimeters results in the following preliminary insights:

- Based on the mould growth experimentally observed for test scheme A (Figure 1a), it can be concluded that the critical relative humidity - or at least $\mathrm{RH}$ min when $\mathrm{T} \geq 20^{\circ} \mathrm{C}-$ in the VTT model (see Hukka and Viitanen, 1999) should be revised. A $\mathrm{RH}_{\min }$ lower than $80 \%$ is plausible. In this respect, it should be noted that Johansson et al. (2013b) mentions in cases of a temperature equal to $22{ }^{\circ} \mathrm{C}$ for pine sapwood a critical relative humidity between $75 \%$ and $79 \%$.

- The rather large standard deviation on the experimental results (Nielsen et al., 2004) indicates the need of expanding the existing deterministic prediction models to stochastic models. Based on the deterministic models, it is preferable that the models predict the maximum mould growth or the average mould growth (in combination with e.g. the $90^{\text {th }}$ percentile). Especially the underestimations indicated in Table 3 should be solved. The large deviation found in experimental studies furthermore indicates the need to inspect a larger number of samples.

- As shown based on test scheme $B$, the risk to simulate an overestimation of the mould coverage based on the WUFI-Bio mould index is mainly existent when the 
mould growth is calculated for longer periods (see Table 3). Note that in the comparison for a one-year period of fictitious cycles as performed in (Vereecken and Roels, 2012) a large WUFI-Bio mould index was found as well. This could be attributed to the absence of a decline during unfavourable periods. For shorter incubation periods, an underestimation could be obtained. The comparison in the current study showed for the VTT mould indices a potential underestimation of the mould risk.

- The influence of the duration of unfavourable conditions and its implementation in the mould prediction models demand further research.

Due to the rather limited measurement data used for the comparative study, further research is, however, required to confirm these conclusions.

Note also that for the VTT model, in Figure 2 the results for resawn $(\mathrm{SQ}=0)$ samples are shown. The results obtained for original kiln-dried samples $(S Q=1)$ are only slightly higher than obtained for $S Q=0$ (Vereecken, 2013). Thus, a different assumption for the surface quality in the mould prediction model cannot explain potential differences between the experimental and the numerical results.

Furthermore, it is important to note that the incubation conditions given in Table 1 are the conditions in the test chamber, whereas these conditions are implemented as surface conditions in the mould prediction models. Especially for the short relative humidity fluctuations, an equilibrium between air and surface relative humidity might not be achieved. Therefore, the potential influence of this simplification was for the 
test schemes $\mathrm{H}$ and I studied in (Vereecken, 2013). For the studied cases, a comparison with the results found based on the air conditions showed a negligible influence when using the biohygrothermal model. On the other hand, for the VTT model or Sedlbauer's isopleth system, using the air relative humidity instead of the surface relative humidity induced an overestimation of the mould growth. Hence, the large difference between experimental and numerical findings obtained based on Sedlbauer's isopleth system can partially be explained by an error on the applied relative humidity. For the VTT model, however, an even larger difference between experimental and numerical results is found if a potential difference between air and surface relative humidity is taken into account.

Ultimately, it should be mentioned that the inoculation technique applied by Johansson et al. (2013a) could have induced a higher water activity of the samples at the start of the experiment.

\section{Challenges in experimental mould growth research}

The comparison made in the previous section showed some discrepancies between the experimental and numerical predicted results. To justify these differences, in what follows, the complexity of mould growth research will be raised by discussing a number of difficulties and potential (overlooked) influencing factors. Some of these difficulties will be illustrated based on the growth of Apergillus restrictus on an artificial growth medium. It is however important to note that such an artificial growth medium is certainly not used as a substitute for real building materials. 


\section{Experimental conditions: an example}

The mould prediction models currently used in the building physics field are all developed based on experimental studies. Information on the test conditions (e.g. mould species, inoculation technique, etc.) for those studies is, however, scarce or rarely published. Yet, these conditions will largely influence the results (Dantigny et al., 2006). Therefore, in the current section, as an example, the test conditions of the experimental study on the growth of Aspergillus restrictus on an artificial growth medium are described. This methodology description gives already a first view on the experimental complexity of mould research. Based on the described experiment, however, no quantitative mould growth analysis is intended.

\section{$\underline{\text { Mould species }}$}

The experimental investigation is performed for the mould species Aspergillus restrictus. Aspergillus restrictus is a common mould species frequently found in the built environment (Anon., 1991; Sedlbauer, 2001). The germination and growth isopleths for Aspergillus restrictus have been determined by Smith and Hill (1982). To obtain mould spores, in a first step freeze-dried strains (Aspergillus restrictus G. Smith, Mycology \& Aerobiology IHEM Culture Collection, IHEM number 818, freezedried batch) were used to inoculate a wire loop used for the inoculation of an artificial growth medium. After ten days of incubation (at $25^{\circ} \mathrm{C}$ ), spores were harvested by use of a wash buffer (PBS (Phosphate Buffered Saline) + 0.05\% Tween80). Since hyphae could have come loose as well during this harvesting process, in a next step 
the harvested spores (and hyphae) suspension was filtered by use of Pasteur pipettes with glass wool and washed twice by centrifugation (at 3000 rcf at $4{ }^{\circ} \mathrm{C}$ for 5 minutes) and resuspension in PBS with Tween80. The total absence of hyphae in a spore suspension obtained based on the procedure mentioned above cannot be fully guaranteed. Though, a microscopic analysis of the spore suspension used in the current study showed very little hyphae. The spore suspension was stored at $4{ }^{\circ} \mathrm{C}$ till the next day.

\section{Substrate medium}

Isopleths found in the literature are often developed for a so-called optimal substrate medium such as an artificial growth medium (Ayerst, 1969; Smith and Hill; 1982; Magan and Lacey, 1984). A full description of the substrate medium is, however, not always given. Yet, the type of artificial growth medium can largely influence the mould growth on it. The optimal substrate medium depends on the mould species.

The substrate medium used in the current study is Harrold's M40Y agar (4.25 g malt extract, $1.25 \mathrm{~g}$ yeasy extract, $100 \mathrm{~g}$ sucrose and $5 \mathrm{~g}$ agar (no bacteriological) per 500 $\mathrm{ml}$ distilled water). M40Y is an optimal substrate medium for Aspergillus restrictus. After preparation, the artificial growth medium was sterilized by autoclaving, cooled and casted in sterile Petri dishes. In the literature, values between 0.89 (Andrews and Pitt, 1987 in Petrovic et al., 2000) and 0.95 (Aihara et al., 2002) are found for the water activity of M40Y. 


\section{$\underline{\text { Inoculation }}$}

In the current study, $4 \mu \mathrm{l}$ of the spore suspension of $A$. restrictus was inoculated on M40Y agar. The spore suspension was prepared the day before the inoculation (the spore suspension was less than 24 hours old). The inoculation is performed by pipetting the spore suspension on the artificial growth medium. Sterile glass beads were used to spread the suspension. Note that this technique is no standard technique in the building physics field, but rather used in the micro-biology (Waldo, 2003; Otta et al., 2014; a.o.). Although the technique can be used when working with artificial growth media, when studying real building materials based on this technique no evenly distributed spore inoculation can be achieved. In the latter case, more traditional techniques in the building physics field, such as spraying the spore suspension, should be applied. Additionally, it is important to be aware of the fact that, for studies on materials, a liquid solution could moisten the sample and, hence, influence the test conditions.

\section{$\underline{\text { Incubation }}$}

The inoculated artificial growth samples are placed in climatic chambers with a constant temperature and relative humidity. The relative humidity in the climatic chambers is achieved by use of saturated salt solutions. Note that if a different method is applied to control the relative humidity $(\mathrm{RH}), \mathrm{RH}$ sensors should be used to measure the relative humidity. Most of those sensors are not accurate at high relative 
humidity. In the literature, often only few information on the incubation technique is given. Hence, caution is required when interpreting the results.

\section{Mould growth investigation}

The mould growth is inspected with a stereo microscope (Zeiss SteREO Discovery.V12 with a PlanoPro lens $1.5 x$ magnification). The microscopic images are made with a AxioCamErc5s ( $2960 \times 1920 \approx 5.0$ Megapixels). To study the mould growth rate, an identical positioning of the sample during the microscopic investigation is important. In the current study, the petri dishes were glued to a square plexi slide which were placed in a positioning frame. Positioning algorithms could be an alternative. Additionally, the entire samples were inspected with the naked eye.

\section{Remarks on experimental mould research}

In what follows some difficulties in the mould growth research are enumerated. The list is, however, probably not exhaustive.

\section{Definition of germination}

In several mould prediction models, the start of the mould germination process serves as a mould risk criteria. An accurate assessment of the start of the germination process is, however, difficult when studying real building materials. Moreover, several definitions for the start of mould germination can be found in the literature, e.g.: 
- a spore has germinated when the length of the germ tube exceeds the spore diameter (Luz and Fargues, 1997);

- a spore has germinated when the length of the germ tube is between one half and twice the spore diameter, depending on the source (Dantigny et al., 2005);

- a spore has germinated when the length of the longest germ tube is greater than or equal to the greatest dimension of the swollen spore (Dantigny et al., 2006).

The applied definition can have an important effect on the germination time (Dantigny et al., 2006). In addition, also for the germination time different definitions can be found, e.g.:

- time at which visible mycelium appears on the inoculated points (El Halouat and Debevere, 1997 in Dantigny et al., 2006);

- time at which a specified percentage of the inoculated spores (e.g. $10 \%, 50 \%$, 90\%) has germinated (Dantigny et al., 2002; Dantigny et al., 2006).

For a more extended overview of definitions, the reader is referred to Dantigny et al. (2006). The difference in definitions hampers an accurate comparison between literature data. Note that, more specific for the mould prediction models commonly used in the building physics area (Vereecken and Roels, 2012), the applied definition for the germination (time) is not given. 


\section{Definition of mould growth}

For the indication of the mould growth, different measurement methods exist. A frequently used assessment method is the measurement of the average increase of the colony along two perpendicular diameters (Trinci, 1969; Gervais et al., 1988). Note, however, that - although the definition seems rather simple - in practice an unequal growth of the fungal hyphae (e.g. Figure 3) could complicate the applicability. Additionally, for aerial hyphae the definition should be extended and other aspects of a colony (e.g. color, branching, thickness of the colony, etc.) are indicative as well (Taniwaki et al., 2006). Again, in the building physics field, the exact definition applied to determine the mould growth in the mould prediction models (Vereecken and Roels, 2012) is often not mentioned by the developers of those models.
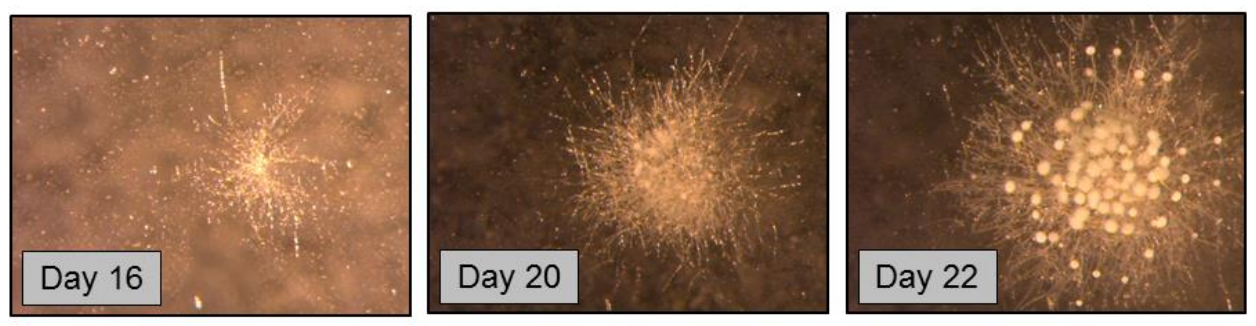

Figure 3. Example of unequal growth of fungal hyphae $\left(24 \mathrm{~h} 86 \% \mathrm{RH}-24 \mathrm{~h} 54 \% \mathrm{RH}, 23{ }^{\circ} \mathrm{C}, 40 \mathrm{x}\right.$ magnification). 


\section{$\underline{\text { Inoculation technique }}$}

The inoculation technique might influence the percentage of mould coverage, and hence the mould index, as well. Evenly distributed mould spores are desirable in experimental studies of the mould index. On the other hand, to measure the mould growth in millimeters, individual mould spore spots are preferred. Note also that where in the current study the investigated substrates were inoculated with a mould spore suspension (active inoculation), in reality mould spores should settle on the substrate (passive inoculation). As an example, Figure 4 compares the mould growth development on an inoculated artificial growth medium with the mould growth development on an artificial growth medium initially free of mould spores but stored in the test room wherein mould growth experiments with the Aspergillus restrictus species had taken place before. Where in cases of the active inoculation a dense mould growth is observed, the passive inoculation results in a sparse growth characterised by individual mould spots which are initiated at a later time. It should however be noted that, during the passive inoculation test, the spore concentration in the air was different from the spore concentration of the spore suspension used for active inoculation. In case of passive inoculation the time till germination and the mould growth density is expected to depend on the mould spore concentration in the test room. Note also that in the current study sterile artificial growth media are used. In cases of building materials, an initial contamination by mould spores is plausible. 

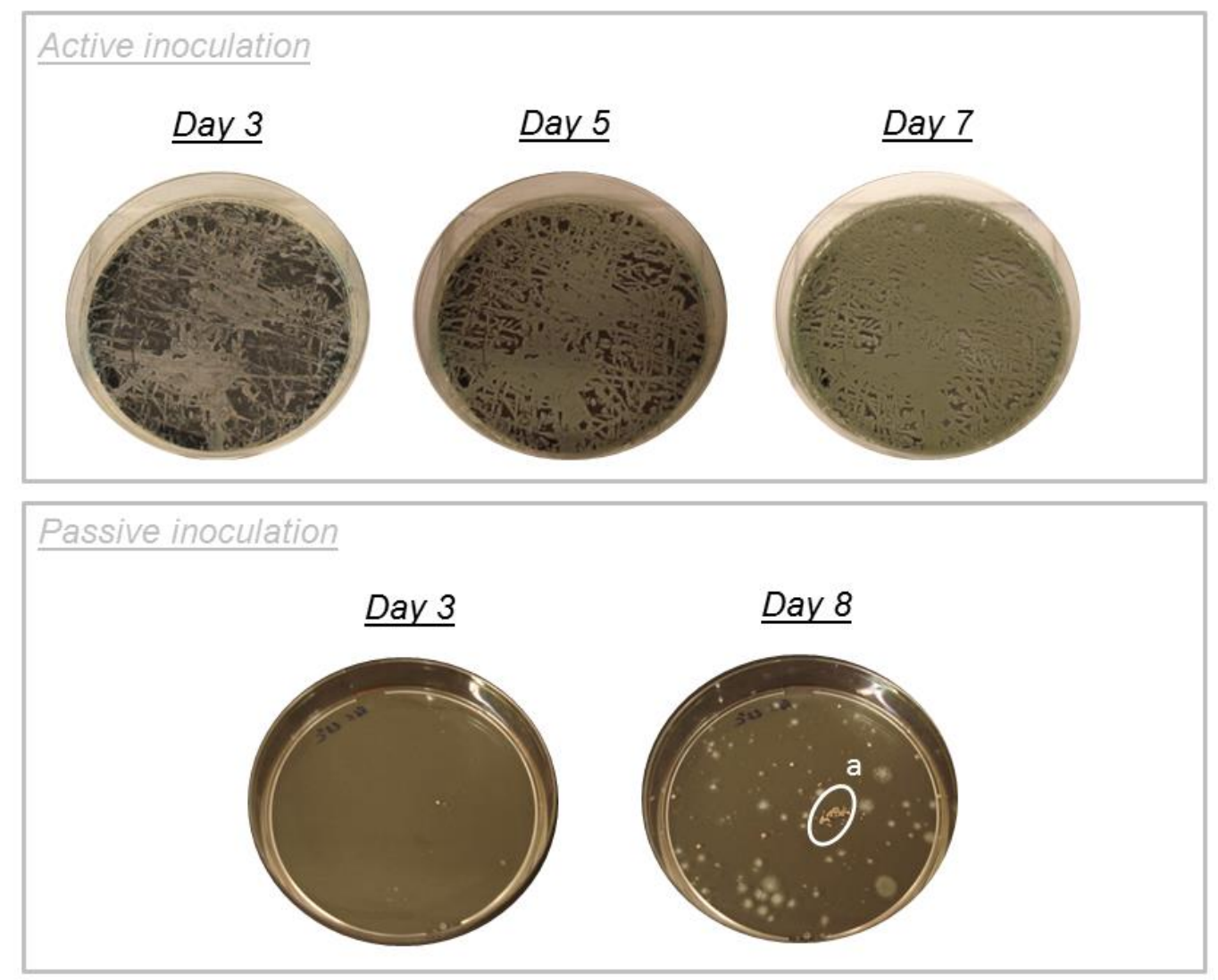

Figure 4. Active versus passive mould spore inoculation: Aspergillus restrictus on a M40Y agar medium exposed to $86 \% \mathrm{RH}$ and $23^{\circ} \mathrm{C}$. Where for the active inoculation a dense mould growth was observed, in cases of the passive inoculation white till light green Aspergillus resctrictus mould spots were only visible after 8 days. A small amount of contamination (indicated by the circle 'a') was found.

\section{$\underline{\text { Probabilistic approach }}$}

As mentioned before, one of the definitions for the germination time suggested in the literature is based on the percentage of spores that have germinated. This indicates a potential spread in the mould growth development. An example of the potential 
spread on the mould growth development is shown in Figure 5. Two selected fields of interest on the artificial growth medium are shown. Both selected fields of interest are totally inoculated with the mould spore suspension. Hence, the large difference cannot be attributed to a lack of mould spores. Where at the field of interest at the bottom right (BR) mycelium growth appears after day 16 (a), at the field of interest at the upper right (UR) first mycelium growth is detected after day 37 (f). At that time, mould coverage at the field of interest at the bottom right is already dense and plenty of conidiophores can already be observed (e). A probabilistic approach is thus pressed forward. 

use of mould prediction models - A critical view on experimental mould growth research. Journal of Building Physics 39(2): 102-123.
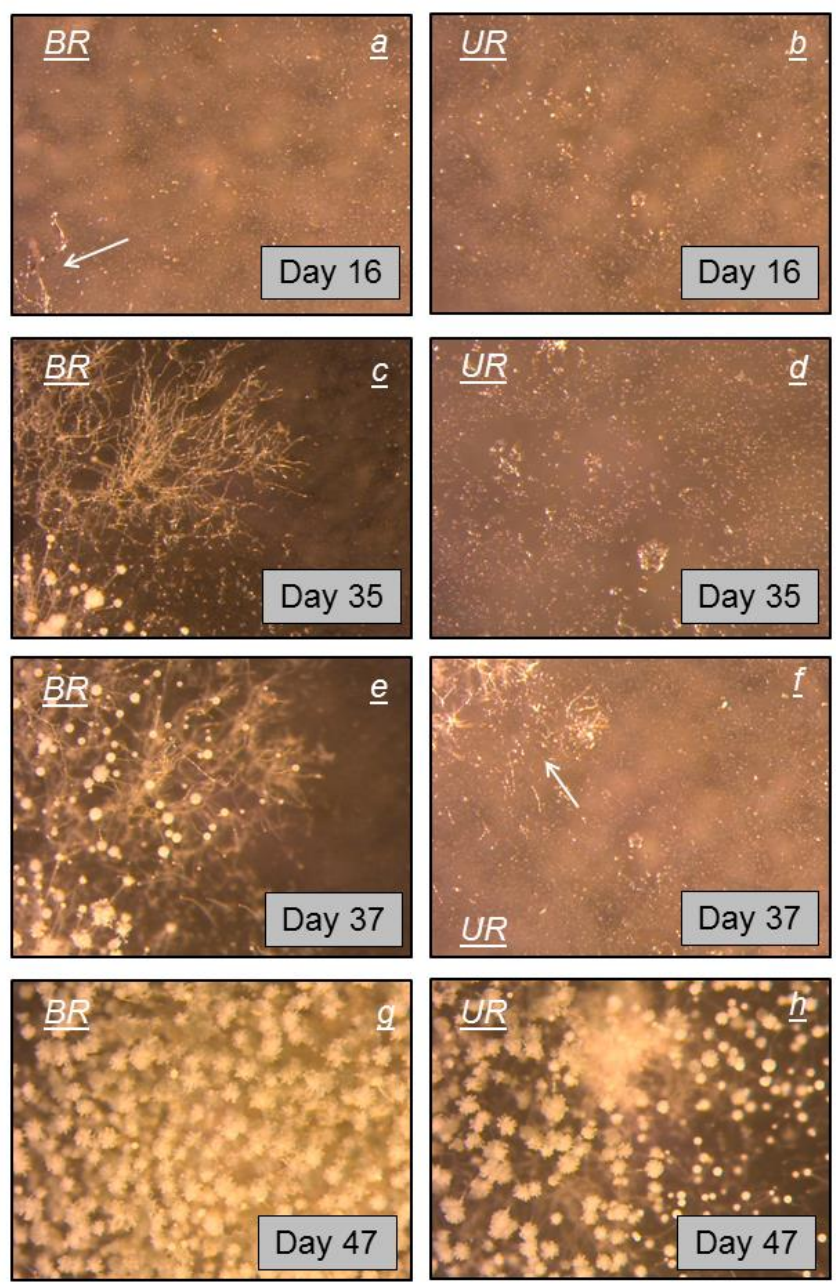

Figure 5. Mould growth development of Aspergillus restrictus on a M40Y agar medium exposed to $24 \mathrm{~h} 86 \% \mathrm{RH} 23^{\circ} \mathrm{C}-24 \mathrm{~h} 86 \% \mathrm{RH} 15^{\circ} \mathrm{C}$ cycles by $60 x$ magnification: $(a, c, e, g)$ field of interest at the bottom right (BR), (b,d,f,h) field of interest at the upper right (UR).

Influence of the spore concentration and the physiological state of the spores

Although not experimentally studied here, it should be noted that the spore concentration and the inoculated quantity of spore suspension can influence the 
mould growth risk as well. Due to self-inhibition, a higher spore concentration could even result in a lower percentage of germination (Chitarra et al., 2004; Dantigny and Nanguy, 2009). A link between the mould coverage and the spore concentration is plausible. Since the mould growth development is often indicated by the mould coverage (e.g. Adan, 1994; Viitanen and Ojanen, 2007; Ojanen et al., 2010; Nielsen et al., 2004, etc.) further research of this influence is pressed forward.

To determine the spore concentration of a spore suspension, a counting chamber could be used. Though, this technique gives no information on the viability of the spores. To count viable colonies only, a plate count can be performed (e.g. according to the procedure mentioned in (Tortora et al., 1995)). The disadvantage of the latter technique is, however, that it demands an incubation time of some days, while the fungal spore suspension is preferably used immediately after preparation.

Ultimately, it should be noted that also the age of the spore suspension and other elements defining the physiological state of the spores (Dantigny and Nanguy, 2009) may influence the viability of the spores and hence the results. As a small experiment, a plate count was performed on a spore suspension immediately after harvesting the spores. Two months later, this was redone for the same spore suspension (stored in PBS with Tween, at $4{ }^{\circ} \mathrm{C}$ ). The colony-forming unit obtained in the last measurement was found to be ten times smaller than determined in the first experiment. 


\section{Isopleths as a basis for mould prediction}

Several mould prediction models are based on isopleths (Ayerst, 1969; Smith and Hill, 1982; Clarke et al., 1999; a.o). As an example, Figure 6 shows the isopleth systems developed by Smith and Hill (1982), which indicate the mould germination and growth of Aspergillus restrictus mould species on an artificial growth medium. The development of isopleths is, however, a quite hard task. First of all, when developing these isopleths based on artificial growth media, different artificial growth media should be prepared, as each artificial growth medium has a specific water activity. This water activity could, for instance, be controlled by use of glycerol, glucose, fructose, sorbitol or $\mathrm{NaCl}$ (e.g. Andrews and Pitt, 1987; Luz and Fargeus, 1997; Valik et al., 1999; Sautour et al., 2001a, Sautour et al., 2001b). Though, for some fungi the type of solute used to control the water activity of the artificial growth medium is found to influence the fungal growth, especially in cases of $\mathrm{NaCl}$ (Pitt and Hocking, 1977; Andrews and Pitt, 1987). The water activity of the artificial growth medium should, furthermore, be in equilibrium with the air relative humidity.

In addition, several measurement points are needed to achieve the isopleth curves. And still, the reliability of those curves can be questioned based on the remarks made above (different definitions for germination and mycelium growth, impact of the inoculation technique, stochastic behaviour, etc.). If the mould growth development is analysed with the naked eye, a human factor will even enforce the potential error on isopleth systems. 
(a)

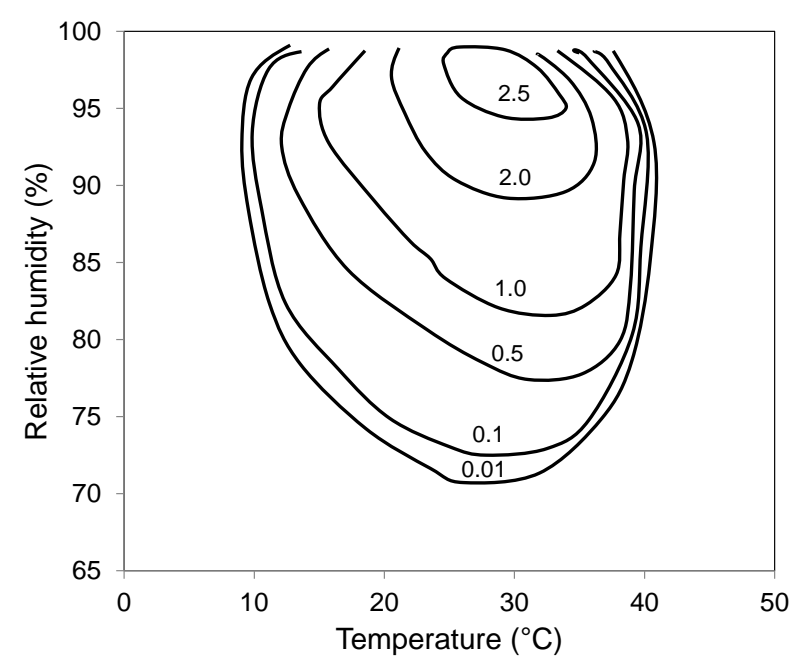

(b)

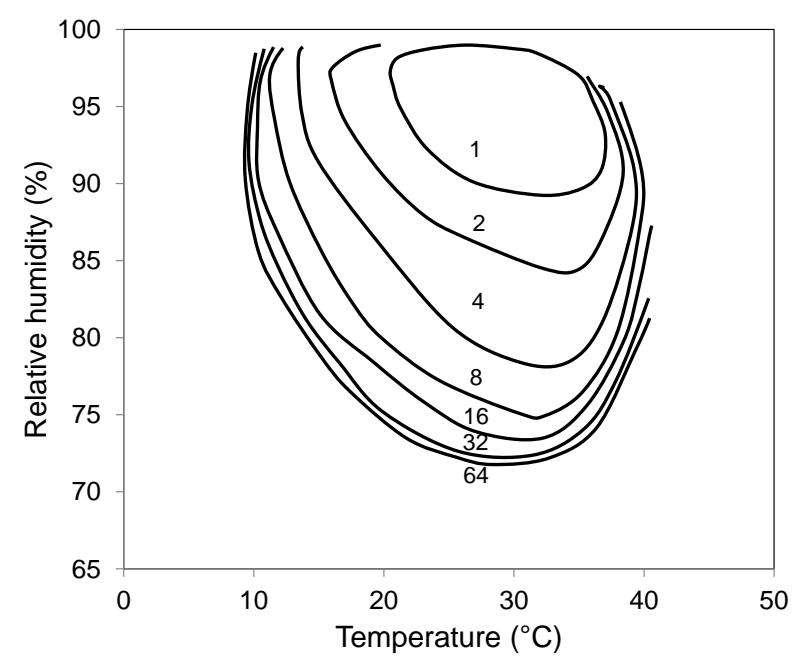

Figure 6. Isopleth system for Aspergillus restrictus (Smith and Hill, 1982): (a) germination isopleths (in days), (b) growth isopleths (in $\mathrm{mm} / \mathrm{day}$ ).

\section{$\underline{\text { Transient studies }}$}

Periods of favourable conditions interrupted by periods of unfavourable conditions could induce special microbiological phenomena, making mould growth under transient conditions a widely studied - though not solved - problem (e.g. Adan, 1994; Viitanen and Bjurman, 1995; Li and Wadso, 2013; Johansson et al., 2013a; Bekker, 2014).

In addition, the potential impact on the surface conditions due to the transient conditions should be considered. In cases of an agar substrate, a gradient of water potential across the agar interface occurs when studying transient conditions. This hampers the agreement between the water activity of the artificial growth medium 
and the fractional air relative humidity (Adan and Samson, 2011). Artificial growth media exposed to a lower relative humidity will dry out, which will result in a decrease of the water activity. After the dehydration of the artificial growth medium, the original water activity cannot be achieved anymore. Hence, to obtain reliable measurements, the artificial growth medium should be used in an environment with a fractional air relative humidity equal to the water activity of the artificial growth medium. All this complicates an investigation of mould growth under transient conditions based on artificial growth media. A suggestion to study transient conditions was, however, recently made by Bekker (2014). She proposed the use of a membrane to perform transient studies on artificial growth media. This membrane can be positioned on the artificial growth medium and the mould species can be inoculated on the membrane. The membrane bearing the growing colony could in a next step be transferred between different artificial growth media.

Also when studying real building materials, hygric buffering could occur in cases of transient conditions. To limit this behaviour when studying building materials, the sample thickness should be as thin as possible, especially for hygroscopic buffering materials (e.g. for wood a thickness less than $1 \mathrm{~mm}$ is recommended).

\section{Microbiological complexity}

Mould growth remains a highly complex microbiological process consisting of hyphal tip extension, hyphal branching, conidiophore formation, sporulation, etc. Small differences in water activity, temperature, nutrient availability, stress conditions, etc. can induce totally different microbiological processes. 


\section{Concluding remarks}

Mould growth is a complex microbiological process, which is difficult to convert in reliable and applicable mould prediction models. As shown in (Vereecken and Roels, 2012), due to the simplifications and assumptions made in the mould prediction models currently used in the building physics field, different conclusions may be drawn depending on the applied model.

The current paper showed a preliminary study on the validity of the main mould prediction models. Thereto, in a first part, a comparison between experimental literature data and the mould growth predicted by use of these models was completed. Especially the implementation of the mould growth under transient conditions demands still a more in depth study to improve the reliability of the current mould prediction models. Whereas based on the measurements performed by Johansson et al. (2013a) and other researchers (e.g. Adan, 1994) long periods of unfavourable conditions are found to result in a larger decrease of the mould growth than found for short periods, this was not pronounced based on the mould prediction models. Though, also for some steady-state conditions a large difference between measurements and simulations was found. It is, however, important to note that the current study does not solve the problem of the discrepancies between the different mould prediction models nor aims to make any suggestions in respect to the most reliable model. 
As pointed out in a second part of the paper, collecting reliable mould growth data and, hence, the development of reliable models is challenging. Some remarks related to the mould growth research were listed. For an experiment performed on an artificial growth medium, the methodology used to obtain the mould spores, the inoculation, etc. was described. As mentioned in Dantigny et al. (2006), these elements may have an influence on the germination kinetics. Thus, to enable an accurate comparison between different literature data, the latter conditions should be listed. In the literature, however, this information is often lacking. The influence of the mentioned parameters demands further research. Additionally, based on both the experimental literature data and the remarks on experimental mould research that were shifted forward, the potential spread in results was broached. The latter indicates the need to expand the current deterministic models to stochastic models. To end, it should be noted that the influencing factors listed in the second part of the paper could be part of the reasons of the differences between the experimental work and numerical predictions shown in the first part of the paper. Both the experimental studies used for the comparison as the experimental work used for the development of the mould prediction models could contain experimental inaccuracies. Though, based on the description of the studies performed by Nielsen et al. (2004) and Johansson et al. (2013a) we assume that the experimental work used for the comparison in the current study is a well performed laboratory study. The similarity with mould growth in situ remains off course questionable. As regards potential inaccuracies in the experimental results, these are intrinsically part of the developed mould prediction model. Furthermore, contradictions between numerical predictions 
and experimental work when looking at some general facts such as the relation between the length of the period exposed to unfavourable conditions and the mould growth indicate that assumptions and simplifications applied for the development of the models will be part of the problem as well.

Ultimately, it should be remind that the current paper showed solely a preliminary evaluation of mould prediction models, and this to raise the user's awareness of potential assumptions and simplifications in the models, such as the deterministic character, etc., which can result in a different mould risk conclusion. A more in depth study, including more experimental data on wood as well as on other building materials, is required to come to a more refined evaluation of the different models.

\section{Acknowledgements}

The results in this paper have been partially obtained within IWT 3E90050 'Global performance approach and economic analysis of interior insulation with regard to renovation projects' funded by the Flemish Government, KUL OT/09/23 'Towards a reliable application of interior insulation for the retrofit of existing buildings' funded by the KU Leuven and FWO 3E140592 'A stochastic and dynamic risk assessment methodology for mould growth and wood rot on timber frame constructions' funded by FWO-Flanders. These financial supports are gratefully acknowledged. 


\section{References}

Abuku M, Janssen H, Roels S (2009) Impact of wind-driven rain on historic brick wall buildings in a moderately cold and humid climate: Numerical analyses of mould growth risk, indoor climate and energy consumption. Energy and Buildings 41(1): 101-110.

Adan OCG (1994) On the fungal defacement of interior finishes. PhD Thesis, The Netherlands.

Adan O, Samson R (2011) Fundamentals of mold growth in indoor environments and strategies for healthy living. Wageningen Academic Publishers, The Netherlands.

Aihara M, Tanaka T, Ohta T, Takatori K (2002) Effect of temperature and water activity on the growth of Cladosporium cladosporioides. Biocontrol Science 7(3): 193-196.

Andrews S, Pitt Jl (1987) Further studies on the water relations of xerophilic fungi, including some halophiles. Journal of General Microbiology 133: 233-238.

Anon (1991) Condensation and energy: Sourcebook, IEA-exco ECBCS, Report Annex 14, Vol. 1, Acco, Leuven.

Ayerst G (1969) The effect of moisture and temperature on growth and spore germination in some fungi. Journal of Stored Products Research 5: 127-141.

Baughman AV, Arens EA (1996) Indoor humidity and human health - Part I: Literature review of health effects of humidity-influenced indoor pollutants. ASHRAE Transactions 1996; Vol.102 Part 1: 193-211.

Bekker M (2014) Growth of Penicillium rubens after desiccation. PhD Thesis, Technical University Eindhoven, The Netherlands. 
Burr ML, Matthews IP, Arthur RA, Watson HL, Gregory CJ, Dunstan FDJ, et al. (2007) Effects on patients with asthma of eradicating visible indoor mould: a randomised controlled trial. Thorax 62: 767-772.

Chitarra GS, Abee T, Ronbouts FM, Posthumus MA, Dijksterhuis J (2004) Applied and Environmental Microbiology 70(5): 2823-2829.

Clarke JA, Johnstone CM, Kelly NJ, McLean RC, Anderson JA, Rowan NJ, et al. (1999) A technique for the prediction of the conditions leading to mould growth in buildings. Building and Environment 35: 515-521.

Dantigny P, Soares Mansor C, Sautour M, Tchobanov I, Bensoussan M (2002) Relationship between spore germination kinetics and lag time during growth of Mucor racemosus. Letters in Applied Microbiology 35: 395-398.

Dantigny P, Guilmart A, Bensoussan M (2005) Basis of predictive mycology. International Journal of Food Microbiology 100: 187-196.

Dantigny P, Bensoussan M, Vasseur V, Lebrihi A, Buchet C, Ismaili-Alaoui M, Devlieghere F, Roussos S (2006). Standardisation of methods for assessing mould germination: A workshop report. International Journal of Food Microbiology 108: 286-291.

Dantigny P, Nanguy SP-M (2009) Significance of the physiological state of fungal spores. International Journal of Food Microbiology 134: 16-20.

El Halouat A, Debevere JM (1997) Effect of water activity; modified atmosphere packaging and storage temperature on spore germination of moulds isolated from prunes. International Journal of Food Microbiology 35(1): 41-48. 
Gervais P, Bensoussan M, Grajek W (1988) Water activity and water content: comparative effects on the growth of Penicillium roqueforti on a solid substrate. Applied Microbiology and Biotechnology 27: 389-392.

Hens H (1991). Condensation and energy: guidelines and practices, IEA-exco ECBCS, Annex 14, Final Report, Vol. 2, Acco, Leuven.

Hukka A, Viitanen HA (1999) A mathematical model for mould growth on wooden material. Wood Science and Technology 33:475-485.

Johansson P, Bok G, Ekstrand-Tobin A (2013a) The effect of cyclic moisture and temperature on mould growth on wood compared to steady state conditions. Building and Environment 65: 178-184.

Johansson P, Svensson T, Ekstrand-Tobin A (2013b) Validation of critical moisture conditions for mould growth on building materials. Building and Environment 62: 201-209.

Karagiozis A, Salonvaara M (2001) Hygrothermal system-performance of a whole building. Building and Environment 36: 779-787.

Koestler RJ, Koestler VH, Charola AE, Nieto Fernandez FE (Eds.) (2003) Art, Biology and Conservation: Biodeterioration of Works of Art. The Metropolitan Museum of Art, New York.

Krus M, Sedlbauer K (2002) Brauchen wir Gefährdungsklassen für schimmelpilze zur Beurteilung von Baukonstruktionen? (Do we need hazardous classes of mould fungi for the assessment of building parts?), Tagungsbeitrag für das 11 . Bauklimatische Symposium der TU Dresden: 790-802. 
Krus M, Kilian R, Sedlbauer K (2007) Mould growth prediction by computational simulation on historical buildings. Museum Microclimates, T. Padfield \& K. Borchersen (eds.), National Museum of Denmark.

Lacey J (1994) Indoor aerobiology and health. In: Singh J, editor. Building Mycology. London: Chapman \& Hall, p. 77-129.

Langmans J, Roels S (2014) What are the hygrothermal consequences of applying exterior air barriers in timber frame construction in Europe? Journal of Building Performance Simulation, DOI:10.1080/19401493.2014.899733

Li Y, Wadsö L (2013) Fungal activities of indoor moulds on wood as a function of relative humidity during desorption and adsorption processes. Engineering in Life Science 13: 528-535.

Luz C, Fargues J (1997) Temperature and moisture requirements for conidial germination of an isolate of Beaveria, pathogenic to Rhodnius prolixus. Mycopathologia 138: 117-125.

Magan N, Lacey J (1984) Water relations of some Fusarium species from infected wheat ears and grains. Transactions of the British Mycological Society 83(2): 281285.

Moon HJ (2005) Assessing mold risk in buildings uncertainty. PhD Thesis, Georgia Institute of Technology.

Nielsen KF, Holm G, Uttrup LP, Nielsen PA (2004) Mould growth on building materials under low water activities. Influence of humidity and temperature on fungal growth and secondary metabolism. International Biodeterioration \& Biodegradation 54(4): 325-336. 
Ojanen T, Viitanen H, Peuhkuri R, Lähdesmaki K, Vinha J, Salminen K (2010) Mold growth modelling of building structures using sensitivity classes of materials. Proceedings Buildings XI, Florida, December 2010.

Otta K, Feng S-Y, Ito T (2014) Detecting protein-DNA interactions using a modified yeast one-hybrid system. Methods in Molecular Biology 1164: 39-51.

Petrovic U, Gunde-Cimerman N, Zalar P (2000) Xerotolerant mycobiota from high altitude Anapurna soil, Nepal. FEMS Microbiology Letters 182: 339-342.

Piecková E, Jesenská Z (1999) Microscopic fungi in dwellings and their health implications. Annals of Agricultural and Environmental Medicine 6(1): 1-11.

Pitt Jl, Hocking A (1977) Influence of solute hydrogen ion concentration on the water relations of some xerophilic fungi. Journal of General Microbiology 101: 35-40.

Platt SD, Martin CJ, Hunt SM, Lewis CW (1989) Damp housing, mould growth, and symptomatic health state. British Medical Journal 298: 1673-1678.

Sautour M, Dantigny P, Divies C, Bensoussan M (2001a) A temperature-type model for describing the relationship between fungal growth and water activity. International Journal of Food Microbiology 67: 63-69.

Sautour M, Rouget A, Dantigny P, Divies C, Bensoussan M (2001b) Application of Doehlert design to determine the combined effects of temperature, water activity and $\mathrm{pH}$ on conidial germination of Penicillium chrysogenum. Journal of Applied Microbiology 91(5): 900-906.

Sedlbauer K (2001) Beurteilung von Schimmelpilzbildung auf und in Bauteilen, Dissertation Universität Stuttgart. 
Sedlbauer S, Martin K (2003) US 2003/0187579 A1 Method for predicting the formation of mould fungi. United States Patent Application Publication. Oct. 2, 2003.

Smith SL, Hill ST (1982) Influence of temperature and water activity on germination and growth of Aspergillus restrictus and A. versicolor. Transactions of the British Mycological Society 79: 558-560.

Sterflinger K (2010) Fungi: Their role in deterioration of culture heritage. Fungal Biology Review 24: 47-55.

Taniwaki MH, Pitt JI, Hocking AD, Fleet GH (2006) Comparison of hyphal length, ergosterol, mycelium dry weight, and colony diameter for quantifying growth of fungi from foods. Advances in Food Mycology 571: 49-57.

Tortora GJ, Funke BR, Case CL (1995) Microbiology: An introduction. Fifth Edition. The Benjamin/Cummings Publishing Company.

Trinci APJ (1969) A kinetic study of the growth of Aspergillus nidulans and other fungi. Journal of General Microbiology 57: 11-24.

Valik L, Baranyi J, Görner F (1999) Predicting fungal growth: the effect of water activity on Penicillium Roqueforti. International Journal of Food Microbiology 47: 141-146.

Vereecken E (2013) Hygrothermal analysis of interior insulation for renovation projects, PhD Thesis, KU Leuven, Belgium.

Vereecken E, Roels S (2012) Review of mould prediction models and their influence on mould risk evaluation. Building and Environment 51: 296-310. 
Viitanen H, Bjurman J (1995) Mould growth on wood at fluctuating humidity conditions, energy efficiency and energy conservation: policies, programmes and their effectiveness. Material und Organismen 29(1): 27-46.

Viitanen H, Ojanen T (2007) Improved model to predict mold growth in building materials. Thermal Performance of the Exterior Envelopes of Whole Buildings $X-$ Proceedings.

Viitanen H, Vinha J, Salminen K, Ojanen T, Peuhkuri R, Paajanen L, Lähdesmäki K (2010) Moisture and Bio-deterioration Risk of Building Materials and Structures. Journal of Building Physics 33: 201-224.

Waldo G (2003) Improving protein folding efficiency by directed evolution using GFP folding reporter. Methods in Molecular Biology 230: 343-359.

WHO (2009) World Health Organization. WHO guidelines for indoor air quality: dampness and mould. ISBN 9789289041683.

WUFI (2005). WUFI-Bio. http://www.hoki.ibp.fhg.de/wufi/downloads [24/09/2013] WUFI-Bio 3.0 (2011). Rel.3.0.085. Sedlbauer, Krus, Zillig. Fraunhofer Institute for Building Physics. http://www.hoki.ibp.fhg.de/wufi/downloads [07/08/2013] 